\title{
DISPLACEMENT ON THE SAN ANDREAS FAULT SUBSEQUENT TO THE 1966 PARKFIELD EARTHQUAKE
}

\author{
By Stewart W. Smith and Max Wyss
}

\begin{abstract}
Immediately following the 1966 Parkfield earthquake a continuing program of fault displacement measurements was undertaken, and several types of instruments were installed in the fault zone to monitor ground motion. In the year subsequent to the earthquake a maximum of at least $20 \mathrm{~cm}$ of displacement occurred on a $30 \mathrm{~km}$ section of the San Andreas fault, which far exceeded the surficial displacement at the time of the earthquake. The rate of displacement decreased logarithmically during this period in a manner similar to that of the decrease in aftershock activity. After the initial high rate of activity it could be seen that most of the displacement was occurring in 4-6 day epochs of rapid creep following local aftershocks. The variation of fault displacement along the surface trace was measured and shown to be consistent with a vertical fault surface $44 \mathrm{~km}$ long and $14 \mathrm{~km}$ deep, along which a shear stress of 2.4 bars was relieved.
\end{abstract}

\section{INTRODUCTION}

The Parkfield-Cholame region is at the northernmost extremity of the segment of the San Andreas fault that was associated with the great earthquake of 1857. This area has been subjected to earthquakes of about Magnitude 6 accompanied by surface faulting four times during this century. The most recent of these events occurred on June 27, 1966 and is the subject of this paper. An index map illustrating the extent of surface faulting in historic times and the currently active areas of the San Andreas fault is shown in Figure 1.

Because of the special geodetic control in the area, the presence of a net of strongmotion seismographs, and the large number of independent and detailed field investigations undertaken in the region immediately after the main shock, more is known about the fault motion associated with this earthquake than with any previous event of comparable size. We will present detailed measurements of fault motion as a function of position along the surface trace, the time history of creep during the year subsequent to the earthquake, and instrumental observations of fault movement that accompanied local aftershocks. Using these data, a determination is made of the dimension of the fault surface, the amount of slip, and the stress release.

In the discussion that follows it will be important to keep in mind that the area under study is a transition region between the now quiet branch of the San Andreas in the Carizzo Plains and the active areas to the north, see Figure 1. Creep has been documented on the San Andreas, Calaveras and Hayward faults some $130 \mathrm{~km}$ to the north, Tocher (1960), Cluff and Steinbrugge (1966), Radbruch and Lennert (1966). Furthermore, Wallace and Brown (1968) have shown that considerable creep has occurred during the past half century as far south as Cholame, but that within a few kilometers south of Cholame all creep activity ceases. That the area under study is characterized by continuing moderate seismic activity, surface faulting, and high creep rates is no doubt related to its transitional nature. 


\section{Measurements}

Prior to the Parkfield earthquake of 27 June 1966 indications of surficial displacement along the San Andreas fault scarp in the Cholame Valley were noticed by Allen and Smith (1966). Fresh en-echelon cracks on the Taylor Ranch $1.7 \mathrm{~km}$ southeast of

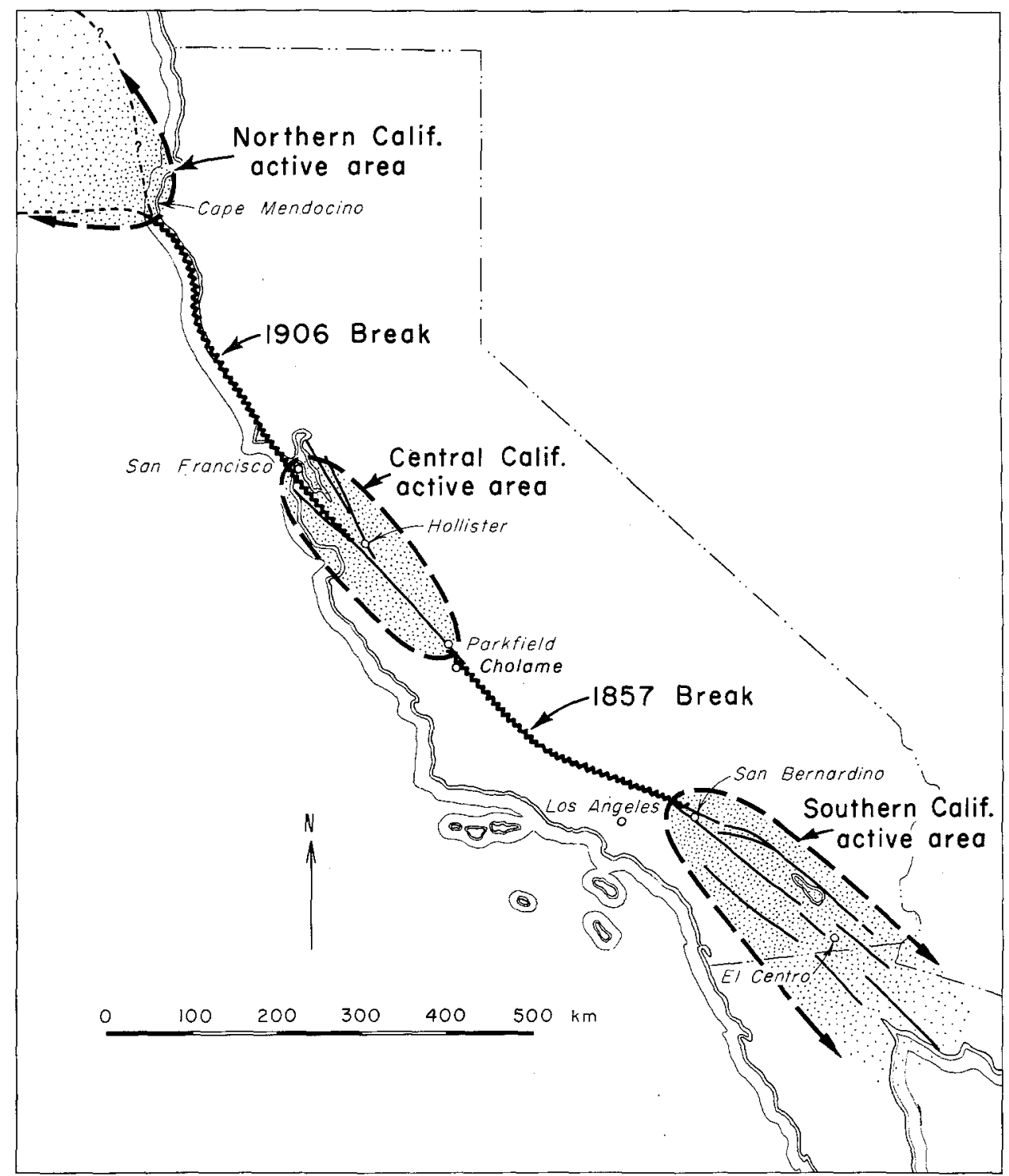

FIG. 1. Map of California showing the San Andreas fault with seismic active areas and locations of historic surface breakage, from Allen (1968). The region under investigation lies between Parkfield and Cholame.

Parkfield were inspected on 16 June by the Second U. S.-Japanese Conference on Research Related to Earthquake Prediction. On 18-19 June, a site near the center of the subsequent activity was occupied with a portable seismograph. A 24-hour record showed no identifiable micro-earthquakes $(\mathrm{M} \geqq 1$ ) within $24 \mathrm{~km}$ (Brune and Allen, 1967). Because the field evidence for fault motion was quite strong, and despite the 
lack of micro earthquakes, the authors planned a small scale geodetic survey across the fault southeast of Parkfield. This work was to start on 28 June 1966 and the field equipment was packed and ready for departure when the earthquake of 27 June occurred. Although it was suspected that the main shock had released most of the tectonic strain in the Cholame Valley, three small-scale geodetic networks, Taylor Ranch, Carr Ranch, and Highway 46 (Figure 2), were established across the fresh fault trace on 29 and 30 June and 1 July respectively. Since during the first week of July the theodolite measurements at the Taylor Ranch revealed a continuing displacement of about $10 \mathrm{~mm} /$ day, three more stations, Parkfield, Peacock, and Cemetery



FIG. 2. Map of the Parkfield region showing the surface break associated with the 1966 earthquake as solid line. Where no rupture occurred the most recent trace of the San Andreas fault is marked by a dotted line. The locations of small-scale geodetic stations are indicated by open circles, those of quadrilaterals established by the USGS as open triangles.

were established on 7 July. In addition, for a special study of fault motion, a tiltmeter and a strain meter were installed at Carr Ranch on 4 July. After U. S. Geological Survey personnel had mapped the extent of the fresh fault trace, a seventh station, Classen, was established on 26 August. As a result of the measurements at this locality, which indicated that the maximum rate of displacement was migrating to the north, two more stations, Mustang Grade and Slack Canyon, were established on 5 May and 7 June 1967 respectively. The locations of these stations are shown in Figure 2 along with the most recent trace of the San Andreas fault, and their coordinates are given in Table 1.

Inasmuch as the earthquake occurred at night (2126 PDT), nothing is known of the surface faulting, if any, that accompanied the main shock itself; indeed, it may 
have been nil. All that is positively known is that by 0700 PDT the following morning, the displacement of the white line at the Highway 46 locality was $4.5 \mathrm{~cm}$. During the morning, displacements of the same order of magnitude were observed at several localities as far north as Taylor Ranch. By evening, the displacement at Highway 46 had increased to $6.4 \mathrm{~cm}$ and was $7.5 \mathrm{~cm}$ by the following noon (Allen and Smith, 1966).

During the month following the Parkfield earthquake the relative displacement was measured geodetically at intervals of about three days. To the end of 1966 it was measured every ten days and thereafter about every thirty days. A continuous record of the quartz strain meter installed across the fault was obtained for the period of 9 July to 18 September 1966. In February, 1967 a less sensitive strain meter was installed in the place of the old one and operated continuously up to date. The tiltmeter was in operation from 4 July to 15 October 1966.

Strainmeter. As soon as it became apparent that significant fault displacement was continuing to occur subsequent to the main shock of June 27 , instrumentation was installed across the fault to record this motion. By July 4, 1966 a tiltmeter and strain meter were operating at the Carr Ranch south of Parkfield. The strain meter consisted of an $8 \mathrm{~m}$ length of fused quartz buried in a trench $2 \mathrm{~m}$ deep. One end was rigidly

TABLE 1

\begin{tabular}{lcc}
\multicolumn{3}{c}{ Coordinates of Geodetic Stations } \\
\hline \multicolumn{1}{c}{ Station } & Latitude & Longitude \\
\hline Highway 46 & $35^{\circ} 44.02$ & $120^{\circ} 17.30$ \\
Carr Ranch & $35^{\circ} 50.15^{\prime}$ & $120^{\circ} 21.90^{\prime}$ \\
Peacock & $35^{\circ} 51.80^{\prime}$ & $120^{\circ} 23.90^{\prime}$ \\
Taylor Ranch & $35^{\circ} 53.18$ & $120^{\circ} 25.42$ \\
Parkfield & $35^{\circ} 54.20$ & $120^{\circ} 26.57$ \\
Classen & $35^{\circ} 57.87$ & $120^{\circ} 31.93$ \\
Slack Canyon & $36^{\circ} 03.75$ & $120^{\circ} 37.54$ \\
Mustang Grade & $36^{\circ} 11.60$ & $120^{\circ} 46.20$ \\
\hline
\end{tabular}

fastened to a concrete pier on the southeast side of the fault, the main body of the quartz was supported by a layer of plastic insulating and packing materials, and a conventional variable capacitor transducer was mounted on a pier on the northwest side of the fault. The sensitivity of this device was limited by daily thermal effects on the surrounding soil. The surface temperature had a daily range of more than $15^{\circ} \mathrm{C}$, the temperature in the insulated channel had a range of about $1^{\circ} \mathrm{C}$, and the observed daily variation of thermal strain was about $10^{-6}$. Since the fault motion continued to be as large as a fraction of a millimeter per day, the thermal effects presented no serious problem.

In a gross sense, the San Andreas rift belt in this region is bounded by granitic rocks of the Gabilan range to the west and Franciscan rocks on the east. Within the rift belt there are numerous exotic fault slices, but the details of the fault contact are generally obscured by Quaternary deposits, Dickenson (1966). That there are gross dissimilarities in the basement rocks on either side of the rift belt can be seen in the results of seismic refraction studies. ${ }^{*}$ The thickness of the alluvium at the site where the strain measurements were made is estimated at several hundred meters. Despite the fact that the fault trace is exposed in alluvium here, the currently active section is very localized, marked by a narrow band of en-echelon cracks, the width of this band being

\footnotetext{
* Personal Communication S. Stewart.
} 
about 5 meters. Furthermore, the observations of residents in the area clearly indicate that cracking occurred within a few meters of the present zone both in 1922 and 1934 . For these reasons it was possible to completely span the fault zone with an instrument of the length described here. Subsequent comparison of geodetic measurement within $1 / 2 \mathrm{~km}$ of this site substantiated the fact that all of the deformation in the rift belt was. actually taking place across this narrow zone.

Tiltmeter. A mercury tiltmeter with a base length of one meter and a free period of 20 seconds was installed at the Carr Ranch within a few meters of the surface cracks representing the trace of the recent fault break. It was located on the southwest side of the fault and oriented parallel to it. Sensitivity was limited to about $10^{-7}$ radian by direct thermal effects on the instrument, which was installed on the surface.



FIG. 3. Map of the geodetic station at Taylor Ranch. The Theodolite station is point number 1 , and the reference points are 2,4 and 7 .

Geodetic Measurements. Figure 3 shows the geodetic station at Taylor Ranch which is typical of the small-scale network used here. The only point occupied with the theodolite was point number 1 . A reference point, number 2 , was chosen such that the direction 1-2 was approximately parallel to the fault. This arrangement minimizes changes of the reference direction due to relative displacement of point 2 with respect to point 1 . On the opposite side of the fault trace a point, number 4 , was chosen such that the angle $\alpha$ was close to $90^{\circ}$. In this way, to a first approximation, only displacement parallel to the fault was measured. Where it was possible, an angle $\beta$, close to $-90^{\circ}$, was measured in order to detect displacement of points on the observers side of the most recent fault trace. This provided a check on the experimental errors and also revealed some interesting information on deformation of the fault zone.

At all stations the theodolite point is marked by a 1 meter long, $2.5 \mathrm{~cm}$ iron bar driven into the ground. The points to be observed are marked by nails in oak trees or telephone poles. For a time scale of a year or so this technique seems well suited for 
rapid installation of small scale networks. It should be emphasized that the time required for installation was a critical factor in the first few days following the earthquake. The distances over which the displacement across the fault were measured vary from 20 to 100 meters. Using a Wild T-2 theodolite, the accuracy achieved was \pm 8 seconds of arc, which for the scale of this survey on the average corresponds to \pm 1.5 $\mathrm{mm}$. Displacements given in this paper are only for the component parallel to the fault.

\section{Discussion}

During the months following the main shock, the strain meter data indicate that steady creep took place along the surface trace of the fault. The creep rate at the Carr

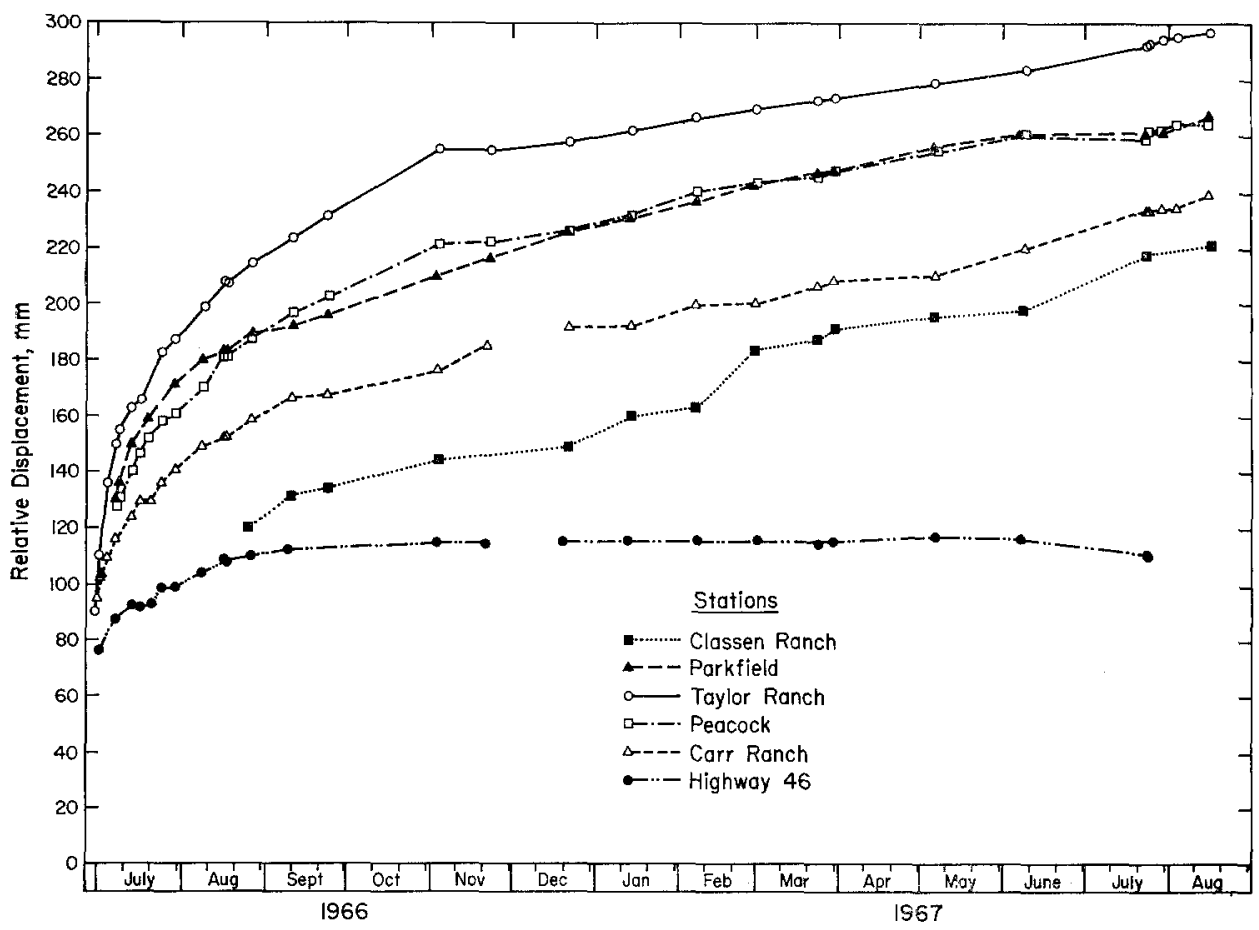

Fig. 4. Cumulative displacement across the fault trace measured geodetically at six stations in the Cholame Valley region. The locations of the stations along the fault are shown in Figure 2.

Ranch varied from .01 to $3.0 \mathrm{~mm} /$ day and was in general confirmed by geodetic observations. Figure 6 demonstrates the fact that although the average rate of creep was $0.9 \mathrm{~mm} /$ day for three months, most of the displacement occurred during short periods at high-creep rates. Some periods of accelerated creep were preceded by aftershocks in the immediate vicinity of the Carr Ranch (Figure 7), and some aftershocks were accompanied by sudden right lateral fault displacement of a few millimeters (Figure 8). Many aftershocks in the Parkfield-Cholame area did not produce any noticeable effects on the strain meter. However, all shocks close enough and large enough to be reported as felt at the Carr Ranch were accompanied by either accelerated periods of creep or sudden fault displacement at that location. The geodetic observations discussed below confirm the fact that the surface displacements associated with these aftershocks $(M<3.5)$ are confirmed to a region within a few $\mathrm{km}$ of the epicenter. It is important to recognize that the correlation is with felt earthquakes only and that all earthquakes reported as felt in the Carr Ranch locality are plotted in. Figure 7. Other earthquakes 
undoubtedly occurred during this time, but these were not reported as felt, and they did not accompany intervals of rapid creep.

The temporary strain meter became unusable following the first heavy rains of the winter. In February, 1967, a less sensitive device was installed across the fault at the
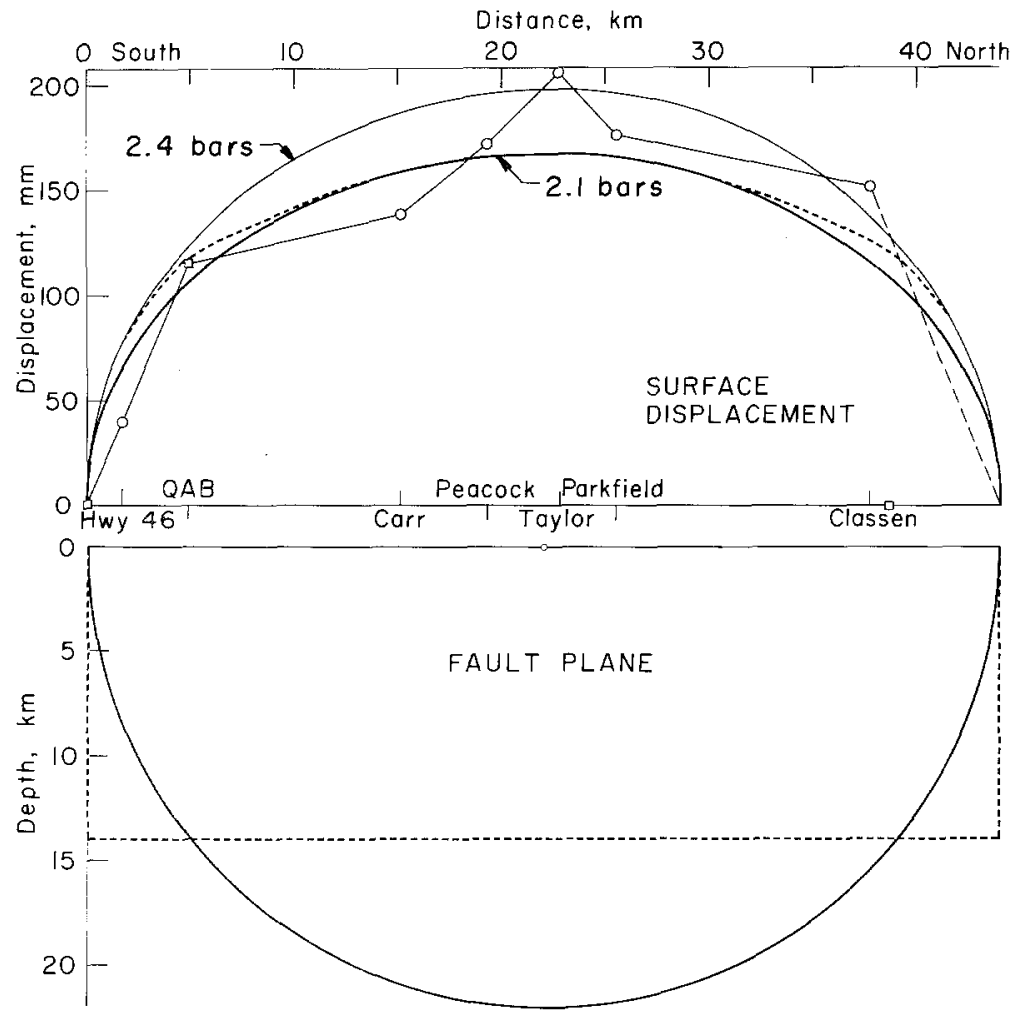

FIG. 5. Fault plane model. The lower part of the figure represents the geometry of two fault plane models. In the upper part of the figure the corresponding theoretical displacements for two values of stress release are compared with the observed displacement accumulated between 30 June 1966 and 16 August 1967. The solid curves correspond to a half-disc model, the dotted to a rectangular one.

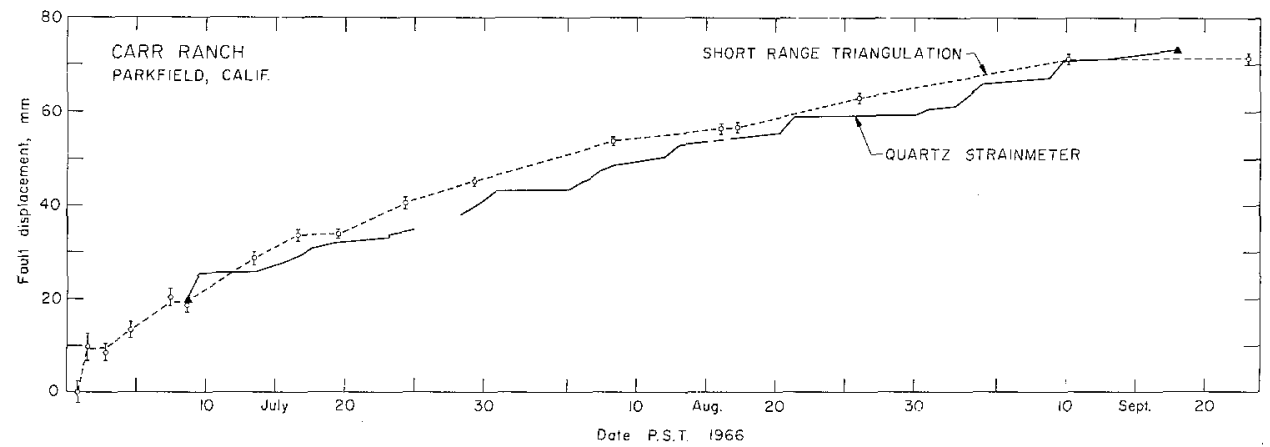

Fig. 6. Comparison of a continuous record of fault movement with geodetic observations at the same site.

same location. The quartz tube was replaced with a taut Invar wire suspended within a $6^{\prime \prime}$ tube. A cantilevered block pivoting on a Teflon bushing provided a constant tension of $20 \mathrm{lbs}$ on the wire. A dial gauge micrometer in contact with this block makes possible manual readings of fault displacement to \pm .0002 inch. A linear-motion potentiometer 
is installed in place of the micrometer for periods during which continuous recording is required.

Figure 7 shows the fault displacement detected by this instrument. The large displacements occurring during the several days following each individual local earthquake are much clearer in this record than they are in Figure 6 where the rate of aftershocks was higher. The predominant mechanism for surface fault displacement here is clearly one of accelerated creep following local shocks. Figure 8 illustrates this on a greatly expanded time scale. The top trace shows normal background noise and a creep rate of less than $0.1 \mathrm{~mm} /$ day prior to the small earthquake on August 19, 1966. At the

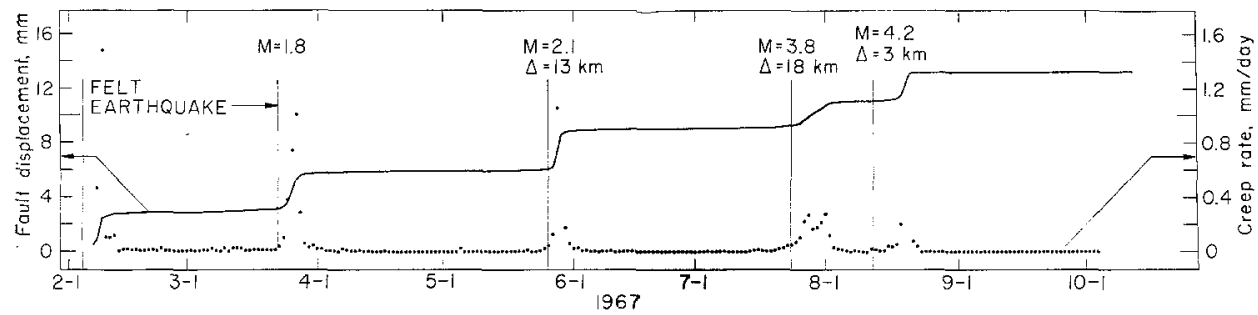

FIG. 7. Cumulative displacement across the fault measured by means of a taut-wire device are shown by the solid line. Daily creep rates are shown by the dotted lines. All earthquakes reported as felt in the locality of the observing station, Carr Ranch, are shown by vertical lines.
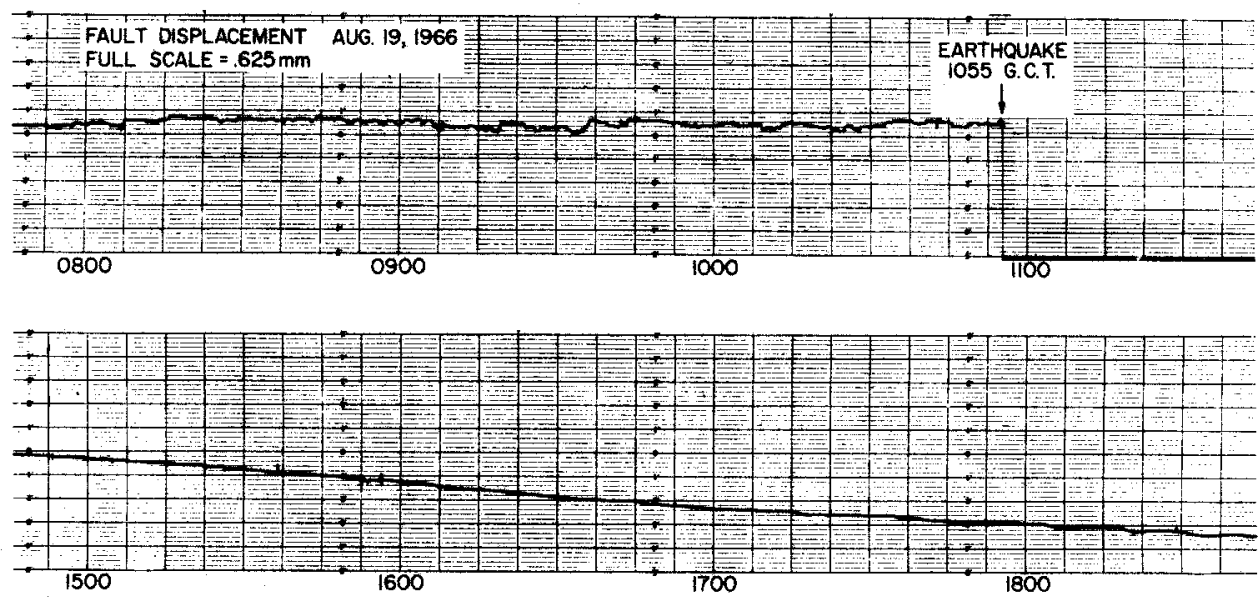

FIG. 8. Record of strainmeter across active section of fault, showing (1) absence of accelerated creep prior to earthquake, (2) actual fault slip during earthquake and (3) high creep rate following earthquake.

time of this earthquake the fault slipped very rapidly, causing the strain meter to go off scale. The total displacement was larger than $0.6 \mathrm{~mm}$ (full scale). The instrument was recentered about four hours later, at which time the strain rate was $2 \mathrm{~mm} /$ day as can be seen in the lower trace. The earthquake responsible for the fault motion occurred at $35^{\circ} 53.8^{\prime} \mathrm{N}, 120^{\circ} 16.6^{\prime} \mathrm{W}$ and had a magnitude of 3.4. From felt reports it must have occurred within a few kilometers of the strain meter location with a shallow depth. A very important feature of this record is the absence of any indication of accelerated creep during the last few minutes prior to the earthquake.

A tilt record is presented in Figure 9. The upper trace shows the response to a small earthquake which occurred nearby on 21 July 1966, but which did not cause fault dis- 
placement at this site. The step-like disturbances before and after the earthquake are instrumental effects and should be ignored. The sense of displacement indicates a large acceleration of the southwest side of the fault toward the northwest, consistent with right-lateral motion. If there is any permanent tilt associated with this earthquake, it is less than $2 \times 10^{-7}$ radians. The shape of the pulse in Figure 9 is about what one would expect if the ground motion had been a step function, and the instrument a critically damped 20 second period pendulum with a displacement transducer. The short-period displacement magnification of this pendulum is 25 . Although the peak value was off scale, it is concluded from the shape of the recorded pulse that the step in displacement must have occurred within a few seconds and have had a total displacement of approximately $2 \mathrm{~mm}$. The differential displacement on the fault, as shown by the strain meter on the lower trace of this same figure, is too small to have produced anything near the acceleration that was sensed by the tiltmeter. Thus, we are led to believe that the ground moved several millimeters northwest during this small (Magnitude 2.3) shock

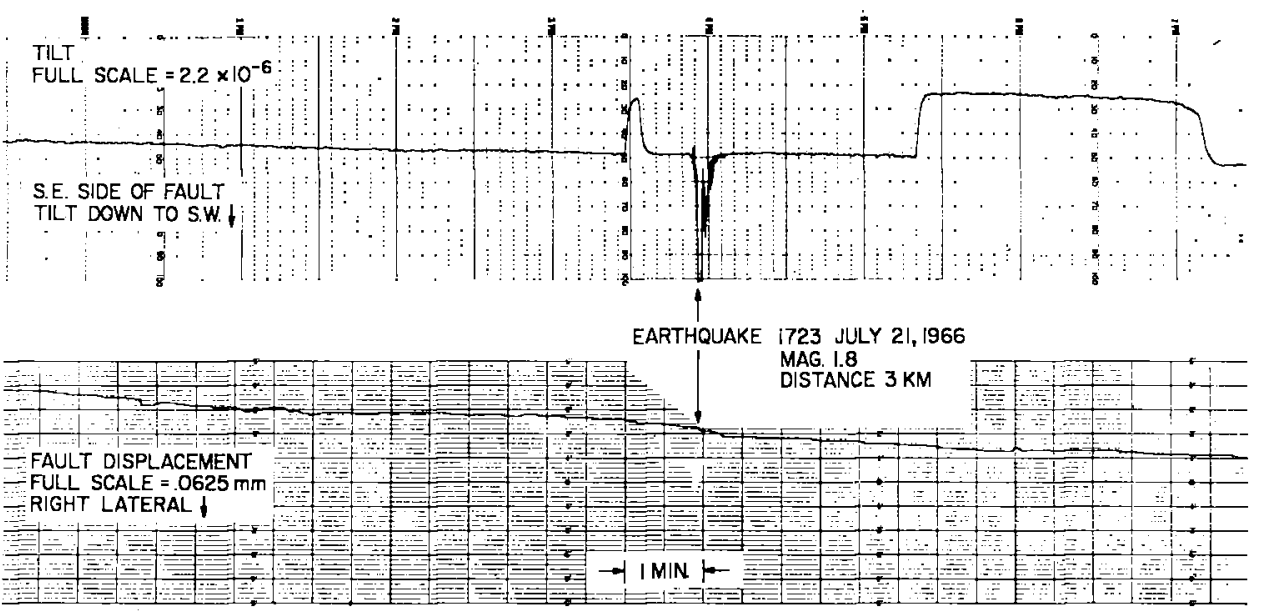

Fig. 9. Record of horizontal pendulum and strainmeter during small aftershock. Transient acceleration shown by pendulum is not accompanied by displacement on the particular branch of the fault spanned by these instruments.

at this site, but that there was no significant slip on the particular branch of the fault spanned by this instrument. We believe this to be direct evidence that significant displacements were occurring on other branches of the fault parallel to and not far removed from the site under consideration. The sense of motion would indicate that, in this case, the slip took place to the east of our station.

It is also of interest to note that no significant tilts occurred prior to this earthquake, and although the aftershocks studied here are much smaller than most of the events for which tilt data are available, it is interesting to make a comparison. For example, Hagiwara and Rikitake (1967) show examples from Matsushiro where tilts of $10^{-7}$ to $5 \times 10^{-7}$ radians preceded earthquakes of magnitude 4.5 . If one assumes that tilting within the source region accompanying an earthquake scales appreximately like the fault length, then tilts of the order of one-tenth of these would have been expected for the small event shown in Figure 9. This is below the limit of long term resolution of the - tiltmeter in use at Parkfield and thus would have escaped detection here.

A summary of geodetic measurements is given in Figure 4 where the displacement parallel to the fault as observed at the different stations is plotted versus time. Since 
the measurements were not started simultaneously at all stations, and since the absolute displacement is known only for the Highway 46 locality, the starting values for the other stations shown in Figure 4 are somewhat arbitrary. The starting values for the earliest measured stations at Carr Ranch and Taylor Ranch were taken so that the observed initial rate of displacement would extrapolate back to zero displacement at the time of the earthquake. The starting value at Peacock was assumed by linear interpolation between the displacements at Carr Ranch and Taylor Ranch on July 7. The similarity of the displacement curves obtained at Peacock and Parkfield together with the displacement distribution along the fault (Figure 5) suggest that the displacement is distributed symmetrically with respect to the center of the fault which appears to be located close to the station Taylor Ranch. The starting values of Parkfield and Classen Ranch were determined assuming the aforementioned symmetry. The zero point of the scale in Figure 4 was chosen such that the first geodetic measurement at Highway 46 was equal to the offset of the white line on the highway at the time of the first measurement. All these assumptions do not influence significantly any of the curves and conclusions discussed here. The flooding that occurred in December, 1966 in the Cholame Valley disturbed the stations Carr Ranch and Highway 46. The creep for the period of 22 November to 21 December was approximated by interpolation of the rates of displacement before and after the flood and added to the accumulated displacement.

The maximum rate of displacement decreased logarithmically from $10 \mathrm{~mm} /$ day two days after the main event to $0.17 \mathrm{~mm} /$ day one year thereafter. During the whole period of measurements the largest amount of total relative displacement was observed at Taylor Ranch. Comparison of these data with the quadrilateral measurements carried out by E. F. Roth (Brown and Vedder, 1967) shows that for a period of one month after the earthquake, displacements at the location QAB were larger than those at Taylor Ranch. Roth obtained displacement values by measuring the length of the sides and diagonals of quadrilaterals. These had the dimensions of 7 to 60 meters and straddled the fracture zone. They were measured repeatedly up to 15 August 1966. The results of two of the 9 quadrilaterals were taken from Brown and Vedder, (1967) and included in Figures 5 and 10 .

The Department of Water Resources (Hofmann, 1968) as well as the U. S. Coast and Geodetic Survey (Meade, 1967) remeasured their geodimeter and triangulation networks across the Cholame Valley following the Parkfield earthquake. The geodimeter network was remeasured between 6 and 27 July, 1967 having previously been measured in October 1965. These results showed that during this time, points $6-8 \mathrm{~km}$ distant from the fault plane moved about $20 \mathrm{~cm}$ in a right lateral sense with respect to points some $12 \mathrm{~km}$ on the other side of the fault. It is likely, in view of the lack of field evidence for creep during this time, that most of the displacement was associated with the earthquake of 27 June.

The frequently repeated geodetic measurements at the various localities resulted in curves with a very similar over-all shape (Figure 4). The large creep rate decreased roughly logarithmically. A more detailed examination of the curves, however, shows that during the time where some stations accumulated a centimeter or more of displacement, others did not move at all. It is evident therefore that the fault moved in segments smaller than the distance between stations which is of the order of $5 \mathrm{~km}$. The same effect can be observed in Figure 10.

Periods of several months during which the rate of displacement at one or the other station was comparatively large with respect to the other stations were followed by periods with a comparatively low displacement rate. The Parkfield station for example 
shows a higher rate of displacement than any other station from July 7 to July 28, 1966. This period must have been preceded by one of low displacement rate, since on July 7 no surface evidence of ground movement could be detected at this locality. From July 28 to November 23, 1966 the fault section including Taylor Ranch and Peacock was the most active one After November 3, the rate of displacement at the Parkfield station was again the largest, until after December 25 when the largest activity was recorded at Classen Ranch. This development suggested that perhaps the fault was migrating to the north. In the very latest period of measurements, June 6 to August 15, 1967, the central portion of the fault was the most active one again. Taylor Ranch showed an increased rate of displacement, and several shocks with magnitudes of about 3.5 occurred.

The stations Mustang Grade and Slack Canyon were established in order to determine the northernmost extent of creep in this region. It was hard to find a well-de-

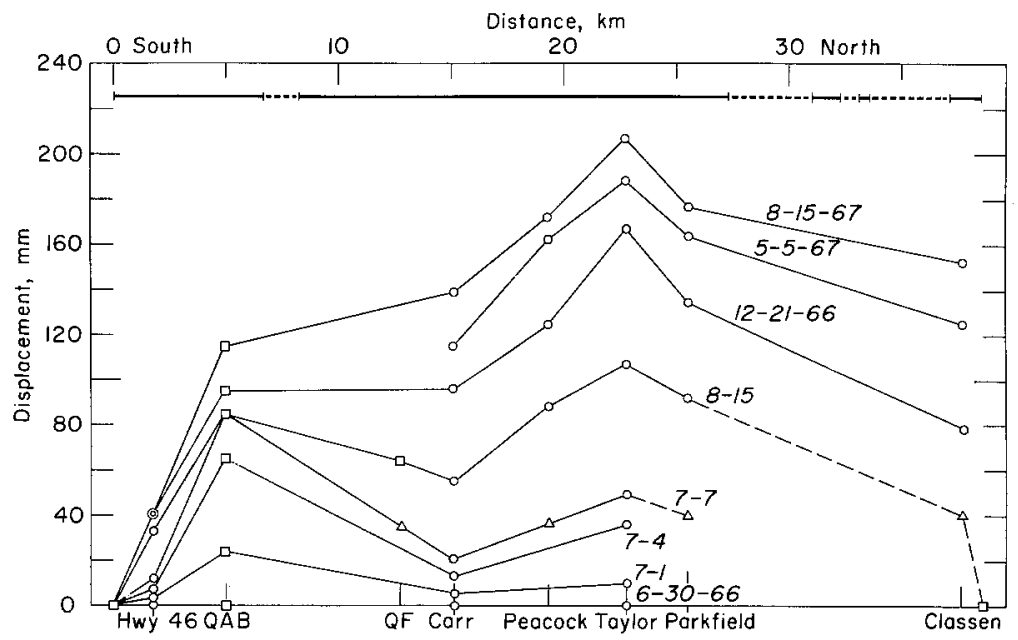

FIG. 10. Cumulative displacement along the fault trace, time is the parameter. Circles mark geodetic measurements, squares mark values taken from Brown et al (1967). Triangles mark the assumed starting values for stations which were established after $30 \mathrm{June} 1966$. The straight line on top symbolizes the fault trace, being solid where surface breakage was observed and dotted where such was absent at the time of the geologic mapping.

veloped fault trace close to and north of Classen Ranch. Numerous landslides obscure the fault trace and, in addition the region is not easily accessible for theodolite measurements. For these reasons the stations were established 12 and $30 \mathrm{~km}$ respectively north of Classen Ranch. At Slack Canyon no displacement was observed. If our observation points do indeed cross the most recent fault trace, the observed displacement at Mustang Grade is not directly related to the Parkfield break but should be linked with the adjacent creep region to the north.

In order to verify the assumption that displacements were occurring parallel to the fault, and to check the observational accuracy of our surveying technique, several alternate points at different angles were measured at both the Parkfield and Peacock localities. In Figure 11 it can be seen that the agreement between different measurements is quite good. Since the angular measurements are converted to displacement parallel to the fault by dividing by the sine of the angle across the fault significant displacement normal to the fault would have produced divergent results in Figure 11.

The solid circles in Figure 11 represent the values of displacement derived from 
angles corresponding to the angle $\beta$ at Taylor Ranch (Figure 3 ). The reference direction was parallel to the fault and the observed point at right angles to it, not across, but away from the fault trace. This angle $\beta$ was originally measured only as a means for checking the internal consistency of the method used for determining fault displacements. Since the points are all on one side of the fault, and there are no surface cracks between them, the relative displacements should remain zero at all times unless the



FIG. 11. Comparison of fault slip and elastic deformation within the fault zone. Open circles and triangles represent deformation of geodetic lines crossing the fault whereas solid circles are obtained from lines lying entirely on one side of the fault. These measurements correspond with the angles $\alpha$ and $\beta$ respectively as shown in Figure 3 .

region is being deformed elastically. It was soon noted that the angle $\beta$ did not remain constant, but occasionally increased for a period of time and later rebounded to approximately its original value. This behavior was very suggestive of the occurrence of recoverable elastic strain in the fault zone. This measurement also showed that at Peacock, Taylor Ranch and Parkfield, the slip and creep displacements are confined to a zone narrower than $20 \mathrm{~m}$; which is consistent with the field observations. The scale for these angles is given in seconds of are on the right side in Figure 10 and is arranged such that the corresponding displacements can be read from the millimeter scale on the 
left. Positive values correspond to right lateral displacement. An interesting phenomenon can be seen in the Taylor Ranch data, an enlarged version of which is shown in Figure 12. The curve representing elastic strain in the fault zone shows two significant increases during the month of July, 1966. The displacement of geodetic marker number 7 shown in Figure 3 during these build-ups is $10 \mathrm{~mm}$ and $6 \mathrm{~mm}$ respectively, and corresponds to a strain of about $10^{-4}$. Each of these build-ups is followed by a strain relaxation of about equal magnitude. In the first example shown in Figure 12, the relaxation occurred sometime between 4 July and $7 \mathrm{July}$, when the geodetic measurements were repeated. During this time two aftershocks occurred within a few kilometers of the Taylor Ranch. The locations for these shocks was obtained from McEvilly et al (1967) and the pertinent data are as follows:

5 July 1966, $6 \mathrm{~km}$ north of Taylor Ranch, depth $3.6 \mathrm{~km}, M=3.1$

7 July 1966, $3 \mathrm{~km}$ north of Taylor Ranch, depth $4.6 \mathrm{~km}, M=3.0$.

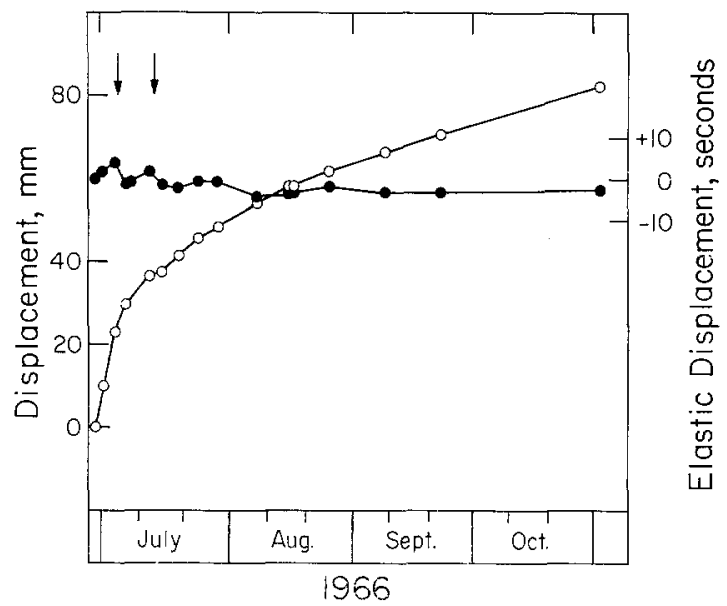

FIG. 12. Possible strain relaxation at Taylor Ranch shown by a decrease in elastic strain (solid circles) and an increase in fault displacement (open circles) accompanying two nearby earthquakes (arrows).

Although we do not know exactly at what time during this interval the displacement of the geodetic reference points took place, it does seem reasonable to associate the observed strain relaxation with the occurrence of these aftershocks. During the same time as the relaxation, a slip of about $12 \mathrm{~mm}$ took place on the fault trace as can be seen on the lower curve in Figure 12. Another possible strain build-up can be seen in mid-July with the subsequent relaxation taking place some time between 13 and 16 July. We note that an aftershock of magnitude 2.8 occurred about $1.5 \mathrm{~km}$ from this site on 14 July. This same aftershock was probably responsible for the strain relaxation that occurred at the Peacock locality (Figure 11) between 16 and 17 July, 1967.

\section{Fault Displacement as a Function of Position}

Many previous field investigations of active faults have revealed that total measured offsets take on a wide range of values over the length of a surface break. In this paper only the creep displacement which occurred subsequent to the initial displacement, which presumably accompanied the main shocks, is studied. The cumlative creep represents a better picture of the total fault displacement occurring at depth than can be obtained from initial surface off set particularly in regions where the initial displace- 
ment may be delayed in reaching the surface due to the flow properties of the near surface materials. In the case of the Parkfield earthquake, the relatively large amplitude of long-period surface waves, $\mathrm{Wu}$ (1968), the large accelerations on nearby strong-motion seismographs, Aki (1968) and the logarithmic creep during the months subsequent to the main shock all lead us to believe that the initial fault displacement at depth must have been considerably larger than the initial surficial displacement that we observed. If large initial displacements occurred at depth on a fault plane extending down to at least $14 \mathrm{~km}$, two types of relaxation would occur, producing delayed and diminished slip on the surface trace of the fault. First, the low strength alluvium, which is approximately $1 / 2 \mathrm{~km}$ thick here, would be subjected to large shear stresses where it is in contact with the faulted basement rocks. The alluvium might be expected to deform plastically as this stress is transmitted upward to the surface. The displacement curve for the Highway 46 locality shown in Figure 4 lends support to this idea, since the projection of the curve back in time yields approximately zero surface displacement at the time of the earthquake. Relaxation of the basement rocks can also be expected in regions where the residual strain is large, such as near the ends of the fault, and in the region around the fault out to a distance of about one fault width. The plastic flow of surface materials will tend to delay and diminish the net slip across the surface-fault trace. The relaxation of stress in the basement rocks however, will not affect the surface slip but will deform the entire Cholame Valley region, causing the long range geodetic data (Hofmann, 1968) to yield an overestimate of the total fault slip.

Not all of the displacement observed in the year following the main shock can be attributed to this mechanism, however. It can be seen in Figure 7 that many individual aftershocks produced fault displacements up to several millimeters and that they were delayed in reaching the surface by as much as one week.

An alternative way to estimate the slip that occurred during the earthquake is to calculate the seismic moment as defined in the dislocation sheory of faulting (see for example, Maruyama, 1963; Haskell, 1963; or Burridge and Knopoff, 1964). In this calculation we need only assume that the fault slip occurred during a time short compared with the period of the seismic waves that we analyze. Using the relation between seismic moment and the area of the envelope of the surface waves which was established for shocks in the Parkfield area by Wyss and Brune (1968), we obtain a moment of $1.9 \times 10^{25}$ dyne-cm for the main shock. Aki (1967) obtained a value of $1 \times 10^{25}$ dyne$\mathrm{cm}$ for the same earthquake. The sum of the moments of the shocks that occurred in the Parkfield region between the 27 June 1966 and 1 January 1968, with moments of at least $1 \times 10^{22}$ dyne-cm, is $\Sigma M_{0}=2.1 \times 10^{25}$ dyne-cm. From this value we compute the average cumulative displacement corresponding to all these shocks using

$$
\Sigma \bar{U}=\frac{\Sigma M_{0}}{A_{0} \mu}
$$

where $\bar{U}$ is the average displacement of one shock, $A_{0}=44 \mathrm{~km} \times 14 \mathrm{~km}$ the total fault area along which the shocks are distributed and $\mu=3 \times 10^{11} \mathrm{dyne} / \mathrm{cm}^{2}$ is the rigidity, and obtain $\Sigma \bar{U}=11.4 \mathrm{~cm}$. The average displacement over the same area for the main shock alone corresponding to a moment of $1.9 \times 10^{25}$ dyne-cm is $10.3 \mathrm{~cm}$. Comparing these two displacement values we conclude that the surface displacements which continued during the year subsequent to the main shock cannot be attributed to aftershock activity alone. The observed average cumulative displacement for the period of 30 June 1966 to 15 August 1967 is about $13.5 \mathrm{~cm}$. The displacement, that occurred be- 
tween the 22 and 30 June 1966 is estimated to be the same as the offset of the white line at Highway 46 that occurred during this time which was $7.5 \mathrm{~mm}$. The total average displacement observed geodetically then amounts to $21 \mathrm{~cm}$. A summary of the displacements determined in different ways is given in Table 2. From these results there appears to be an excess of average displacement of about $10 \mathrm{~cm}$ along the fault which is not reflected in radiated seismic energy. We conclude therefore that a substantial amount of displacement, about $10 \mathrm{~cm}$, was produced by creep occurring over the entire fault surface down to depths of at least $14 \mathrm{~km}$.

In Figure 10 the total fault motion subsequent to June 30,1967 is plotted as a function of position along the fault. The family of curves represents the accumulated displacements at different times during the year following the earthquake.

For the construction of Figure 10 a number of assumptions were necessary. First it was assumed that on June 30 the displacement all along the fault was zero. Of course this assumption is not true. On Highway 46 at Taylor Ranch and on a locality on the Parkfield road, cracks had been observed on the 30th of June, whereas other localities on the Parkfield road, which later showed cracks, had none at that time. The informa-

TABLE 2

Average displacement of the main
shock determined from seismic mo-
ment
Average cumulative displacement cor-
responding to the sum of the seismic
moment of the entire earthquake se-
quence
Total cumulative surface displacement
observed within $100 \mathrm{~m}$ of the fault
trace 27 July-15 August 1967
Displacement for points 5 km distance
from the fault plane by geodimeter
observation between October 1965
and July 1966

tion is not detailed enough that we could complete Figure 10 for the time between 27 and 30 June. Second, the measurements were not started simultaneously. At the Peacock and Parkfield localities they were started on 7 June, at QAB (USGS) on 8 June and at Classen Ranch on 15 August. For Peacock and QAB an initial value was obtained by linear interpolation between the displacements of neighboring stations. The initial value for the Parkfield station was obtained by assuming symmetry of the pattern with respect to the point of maximum displacement, Taylor Ranch. The value of 15 August for Classen Ranch was estimated by extrapolating the displacement versus time curve obtained at this station back to the 30th of June. All these assumed values are marked by triangles in Figure 10.

The extremities of the region of surface cracking as mapped by R. D. Brown and J. G. Vedder were assumed to be points of zero displacement. The mapping was completed on July 15, 1966 (Brown et al, 1967). It is quite likely that subsequently the region of cracking extended beyond these points.

Figure 10 shows that in December 1966, about half a year after the Parkfield earthquake, the fault displacement as a function of position along the fault has reached a pattern which remained stable until August 1967, the last measurement presented in 
this paper. In this pattern, by August 1967, about 80 per cent of the length of the surface break shows an offset of $120 \mathrm{~mm}$ or more. The decrease from this value to zero at the ends of the fault takes place in 10 per cent of the fault length $(4$ to $5 \mathrm{~km}$ ) at the north and south ends. The Taylor Ranch station, located approximately in the middle of the fault trace, displays a conspicuous maximum. Before December 1966 the pattern was different. Small values at the Carr Ranch dominate the picture. For about a month after the earthquakes the displacements at QAB (USGS) close to the south end were larger than the maximum at Taylor Ranch. Since there was no coverage between Carr Ranch and $\mathrm{QAB}$ the straight lines connecting the displacement values of these two stations are questionable. The fault trace crosses from the east side of the valley to the west side $8 \mathrm{~km}$ north of Highway 46 . No surface rupture could be detected along this 1.5 $\mathrm{km}$ long bend in the fault trace, (dotted fault trace in Figure 10). For an interval of time up to a week after the earthquake one could assume zero displacement on this portion. This would explain the early small displacements at Carr Ranch, and would suggest that the two branches of the fault were separate breaks. A connection between the two breaks seems to have established itself between 7 July and 21 December 1966 .

Any simple model in which shear stress is released along a vertical surface would produce a maximum offset at the center of the fault with a rapid decrease near the ends. The mathematical solution for displacements along arbitrary fault surfaces in a prestressed elastic half space are not available. The solution for a disc-shaped surface in a whole space, however, has been given by Keylis-Borok (1959), and it appears to be valid to use this model to make some general conclusions regarding the data presented in Figure 10. The displacement jump across a flat ellipsoidal free surface

$$
\frac{x^{2}}{b^{2}}+\frac{z^{2}}{b^{2}}+\frac{y^{2}}{a^{2}}=1
$$

where a $\rightarrow 0$, inserted in a medium which is subjected to a uniform shear stress $P$ is

$$
u_{x}=\frac{2 P}{\mu} \frac{4 \alpha}{\pi(2+\alpha)} \sqrt{b^{2}-x^{2}-z^{2}}
$$

where

$$
\alpha=\frac{\lambda+2 \mu}{\lambda+\mu}
$$

If we look at the displacements across this surface on the plane $z=0$ they should be similar to those at the surface of a half space generated by a semi-circular stress free surface. In this case, and assuming $\lambda=\mu$, the displacement is

$$
u_{x}=\frac{24 P}{7 \pi \mu} \sqrt{b^{2}-x^{2}}
$$

In Figure 5, the theoretical displacement (solid curve) is compared with the total displacement measured on August 15, 1967. To approximate the shape of the observed pattern, the fault length for the theoretical model had to be extended $5 \mathrm{~km}$ beyond the northern end point mapped in July 1966. The fault length in this model is thus $44 \mathrm{~km}$ 
and the maximum depth $22 \mathrm{~km}$. Aftershocks clearly did not occur at depths greater than about $14 \mathrm{~km}$ in the Parkfield area as was demonstrated by Eaton (1968). We assume that displacement at depths greater than this takes place as creep. Two theoretical curves are drawn in Figure 5; one for a stress drop of 2.4 bars on the fault surface and the other for 2.1 bars. For the displacement data at the present time, the curve for 2.1 bars is a better fit. This curve would be a very good fit to the data if one could smooth out the excess displacement at Taylor Ranch and the defect at Carr Ranch. Since the displacement is still going on, however, the curve with a stress drop of 2.4 bars will probably prove more appropriate for the final displacement value.

Intuitively it is clear that a rectangular fault plane would produce a displacement pattern with larger values near the ends and a steeper drop to zero than is produced by a semi-circular fault plane. The dotted lines in Figure 5 show such a model with a depth of $14 \mathrm{~km}$ and the displacement curve corresponding to it. The displacement values are inferred from experiments in foam rubber.* The comparison of the observed displacement with the theoretical and laboratory curves seems to be slightly in favor of the rectangular model.

The above arguments presuppose a uniform shear stress is applied to the entire region. The observed patterns of displacements could also be explained if the applied stress were concentrated near the center of the fault. Strictly speaking the problem of determining the exact stress and displacement on the fault from surface measurement alone is indeterminate, however, the model proposed would appear to make good physical sense.

\section{CONCLUSIONS}

(1) During the year subsequent to the 1966 Parkfield earthquake a maximum of at least $20 \mathrm{~cm}$ of total displacement occurred on a $30 \mathrm{~km}$ section of the San Andreas fault, which far exceeded the surficial displacement at the time of the earthquake itself. The rate of displacement decreased logarithmically during this period in a manner similar to the decrease in aftershock activity. After the initial high rate of activity it could be seen that most of the displacement was occurring in 4-6 day epochs of rapid creep following local aftershocks.

(2) Comparisons of fault displacement inferred from the seismic moment with those determined from surface geodetic measurements indicate that about half of the total displacement mentioned above occurred during the main shock but was not immediately detected at the surface because of the viscous properties of the nearsurface materials. The remaining half probably occurred as creep on the fault surface itself, and took place so slowly that there was no radiated elastic energy associated with it.

(3) Some epochs of creep appear to commence before the ocurrence of a local shock, while others do not. The relation between the onset of ereep and earthquakes is not yet understood. The correlation of creep epochs with locally felt earthquakes is very strong.

(4) Changes in the rate of creep did not occur simultaneously along the length of the fault trace. Sections as close together as $5 \mathrm{~km}$ would often proceed with significantly different creep rates. The integrated history of creep, however, showed a smooth variation from a maximum near the center to near zero at either end of the surface break.

(5) The variation of total fault displacement along the surface trace was shown to be

\footnotetext{
* Personal communication, J. N. Brune.
} 
consistent with a vertical fault surface $44 \mathrm{~km}$ long and $14 \mathrm{~km}$ deep along which a shear stress of 2.4 bars was relieved.

(6) Several examples of an accumulation of about $10^{-4}$ strain were detected in the fault zone. Relaxation of this strain with the occurrence of nearby aftershocks could also be seen.

(7) Surface cracking indicated that the fault had an en-echelon offset in the southern end of Cholame Valley. Displacement measurements during the first month after the main shock confirmed this and showed that the relative motion across the surface trace died out near the end of one break and was taken up on the other branch further south.

(8) Fault motion occurring during an aftershock was recorded instrumentally. It revealed that the total slip occurred during a few seconds, that this particular earthquake was not preceded by accelerated creep, and that an interval of rapid creep commenced immediately afterward.

\section{ACKNOWLEDGMENTS}

Some of the instrumental recordings of movement of an active fault presented in this paper are unique, and would have been impossible to obtain had it not been for the rapid and efficient installation of instruments immediately following the earthquake. Special thanks are due to W. Gile, R. Gilman, and D. Tanner for making this possible. The continued interest and assistance of $\mathbf{R}$. Carr on whose property the instruments were located, was invaluable. The authors profited from discussions with J. Brune, and from the critical review of the manuseript provided by $\mathrm{C} . \mathrm{R}$. Allen.

This work was supported by the National Seience Foundation grant GP 2806 (Upper Mantle Project) and National Science Foundation grant GA 1087 (Earthquake Mechanisms).

Aki, K. (1967). Scaling law of seismic spectrum, J. Geophys. Res., 72, 1217-1231.

Aki, K. (1968). Seismic Displacements near a fault, $J$. Geophys. Res. in press.

Allen, C. R. (1968). The tectonic environments of seismically active and inactive area along the San Andreas fault system, Proceedings of Conference on Geologic Problems of San Andreas Fault System, Stanford University Publication, California.

Allen, C. R. and S. W. Smith (1966). Parkfield earthquake of June 27-29, 1966, Pre-earthquake and post-earthquake surficial displacement, Bull. Seism. Soc. Am. 56, 955-967.

Brown, R. D., Jr. and J. G. Vedder (1967). Surface tectonic fractures along the San Andreas fault, the Parkfield-Cholame California earthquakes of June-August 1966, Geological Survey Professional Paper 579.

Brune, J. N. and C. R. Allen (1967). A Micro-earthquake survey of the San Andreas fault system in Southern California, Bull. Seism. Soc. Am. 57, 2, 277-296.

Burridge, R. and L. Knopoff (1964). Body force equivalents for seismic dislocation, Bull. Seism. Soc. Am. 54, 1875-1888.

Cluff, L. S. and K. V. Steinbrugge (1966). Creep in the Irvington district, Fremont, California, in tectonic creep in the Hayward fault zone, California, U. S. Geol. Survey Circ. 525, 8-12.

Dickenson, William R. (1966). Structural relationships of San Andreas fault system, Cholame Valley and Castle Mountain Range, California, Geol. Soc. Am. Bull. 77, 707-726.

Eaton, J. P. (1968). Dependence of hypocentre determinations on the distribution of recording stations and the precision of the seismic velocity model of the Earth's crust in the ParkfieldCholame area, Proceedings of Conference on Geologic Problems of the San Andreas Fault System, Stanford University Publications, California.

Hagiwara, T. and T. Ritkitake (1967). Japanese Program on Earthquake Prediction, Science, $157,761-768$.

Haskell, N. A. (1963). Radiation pattern of Rayleigh waves from a fault of arbitrary dip and direction of motion in a homogeneous medium, Bull. Seism. Soc. Am. 53, 619-642.

Hofmann, R. B. (1968). Recent changes in California fault strain from the Department of Water Resources Geodimeter Strain-Monitoring Program, Proceedings of Conference on Geologic Problems of the San Andreas Fault System, Stanford University Publication, California. 
Keylis-Borok, V. I. (1959). On estimation of the displacement in an earthquake source and of source dimensions, Annali Geofisica, 12, 205-214.

Maruyama, T. (1963). On the force equivalent of dynamic elastic dislocations with reference to the earthquake mechanism, Bull. Earthquake Res. Inst., Tokyo Univ. 4l, 467-486.

Meade, B. K. (1967). Report on results of triangulation for Earth movement study, vicinity of Cholame, California, U. S. Coast and Geodetic Survey, Washington Science Center.

McEvilly, T. V., W. M. Bakun and K. B. Casaday (1967). The Parkfield, California earthquakes of 1966, Bull. Seism. Soc. Am. 57, 1221-1244.

Radbruch, D. H. and B. J. Lennert (1966). Damage to culvert under Memorial Stadium, University of California, Berkeley, in tectonic creep in the Hayward fault zone, California, U.S. Geol. Survey Circ. 525, 3-6.

Tocher, Don (1960). Creep on the San Andreas fault-Creep rate and related measurements at Vineyard, California, Bull. Seism. Soc. Am. 50, 3, 396-404.

Wallace, R. and R. D. Brown (1968). Offset stream channels along the San Andreas fault in the southern Coast Ranges, Proceedings of Conference on Geologic Problems of the San Andreas Fault System, Stanford University Publication, California.

Wu, F. (1968). Parkfield earthquake of June 28, 1966, magnitude and source mechanism, Bull. Seism. Soc. Am. 58, 689-709.

Wyss, M. and J. Brune (1968). Seismic moment, stress and source dimensions for earthquakes in the California-Nevada region, J. Geophys. Res. 73, 4681-4694.

SEISMOLOGICAL LABORATORY

California Institute of Technology

Pasadena, California

Division of Geological Sciences Contribution No. 1527.

Manuscript received March 26, 1968. 